\title{
TRANSPARÊNCIA ATIVA: UMA AVALIAÇÃO DOS MUNICÍPIOS DO ESTADO DE MATO GROSSO DO SUL
}

\author{
ACTIVE TRANSPARENCY: AN EVALUATION OF MATO GROSSO DO SUL STATE \\ MUNICIPALITIES
}

\author{
Caio Luis Chiariello \\ Universidade Federal da Grande Dourados, MS, Brasil \\ E-mail: caiomudo@gmail.com \\ Felipe Ferreira Paulucio \\ Mestre em Administração Pública -UFGD, MS, Brasil \\ E-mail: felipepaulucio@yahoo.com.br \\ Ricardo França de Brito \\ Mestre em Administração Pública -UFGD, MS, Brasil \\ E-mail: ricardobrito@ufgd.edu.br \\ Gisele de Souza Assumpção \\ Mestre em Administração Pública -UFGD, MS, Brasil \\ E-mail: giseleassumpcao@ufgd.du.br \\ Morrison Francisco Reis Verão \\ Mestre em Administração Pública -UFGD, MS, Brasil \\ E-mail: morrisonverao@ufgd.edu.br \\ João Batista de Morais \\ Mestre em Administração Pública -UFGD, MS, Brasil \\ E-mail: joaomorais@ifms.edu.br
}

Recebido em: 09.04.2019 - Aceito em: 23.07.2019

DOI: http://dx.doi.org/10.5902/2526629237675

\section{RESUMO}

Com o advento da accountability, termos como transparência e governo eletrônico (e-government), passaram a ser mais usados, e a sociedade brasileira pôde experimentar uma nova era de acesso à informação, regida por normas e leis. Com o intuito de avaliar a transparência da execução orçamentária dos 79 (setenta e nove) municípios do estado de Mato Grosso do Sul, realizou-se uma pesquisa descritiva, por meio de análise documental, com o auxílio de ferramentas quantitativas. Para tanto, desenvolveu-se uma escala de avaliação da transparência pública ativa dos municípios, conforme as informações disponibilizadas pelos seus sítios eletrônicos. A partir dos resultados apresentados, observou-se que não há uma diferença significativa da transparência ativa de acordo com a população ou com o montante de despesas dos municípios. Por fim, notou-se que a maioria 
deles ainda apresentam taxas de transparência incipientes, aquém das obrigações preconizadas pela Lei de Acesso à Informação.

Palavras-Chave: Orçamento; Transparência; Governo Eletrônico; Accountability.

\section{ABSTRACT}

With the advent of accountability, terms such as transparency and e-government became more widely used, and Brazilian society was able to experience a new era of access to information, governed by rules and laws. In order to evaluate the transparency of the budget execution of the 79 (seventy-nine) municipalities of the state of Mato Grosso do Sul, a descriptive research was conducted through document analysis, with the aid of quantitative tools. Therefore, a scale of evaluation of the active public transparency of the municipalities was developed, according to the information provided by their electronic websites. From the results presented, it was observed that there is no significant difference in active transparency according to the population or the amount of expenditure of the municipalities. Finally, it was noted that most of them still have incipient transparency rates, which are below the obligations of the Access to Information Act.

Keywords: Budget; Transparency; Electronic Government; Accountability

\section{INTRODUÇÃO}

A promoção da transparência dos atos da Administração Pública é condição necessária para o exercício da democracia. O direito à informação foi garantido na Constituição Federal de 1988 e evoluiu ao longo do tempo por meio de normas. Dentre elas destacam-se a Lei da Responsabilidade Fiscal (LRF) e a Lei do Acesso à Informação (LAI), que determinam a divulgação de dados relativos ao processo de planejamento e execução orçamentária.

Embora tenha havido avanços, Cruz et al. (2012) evidencia que, ainda hoje, há déficit de accountability na gestão pública brasileira. A promulgação da Lei de Responsabilidade Fiscal (LRF), em 2000, trouxe a obrigatoriedade para a gestão fiscal ter ampla divulgação, inclusive em meios eletrônicos. Porém, essa divulgação tem demonstrado ser precária, por não disponibilizar os dados por meio de uma interface amigável ao usuário comum e dispor de insuficiência de conteúdo (Campos et al., 2013).

Nesse sentido, a promoção da transparência dos governos pode ser dividida em ativa e passiva. Enquanto a transparência ativa traduz-se na divulgação pela Administração Pública de informações à sociedade por iniciativa própria, sem que 
haja qualquer solicitação, na transparência passiva as informações são disponibilizadas sob demanda, em atendimento às solicitações da sociedade (CGU, 2011).

Um passo importante na promoção da transparência pelos governos estaduais e municipais foi a criação de um método para medir a transparência pública dos estados e municípios brasileiros pela Controladoria-Geral da União (CGU) da Escala Brasil Transparente (EBT). Esse indicador mede o grau de cumprimento dos dispositivos da Lei de Acesso à Informação, concentrando-se na avaliação da transparência passiva (CGU, 2016).

O estudo da avaliação da transparência na gestão de entes públicos mostrase importante na medida em que avalia a possibilidade de promoção do controle social dos atos geridos por esse setor. Assim, quanto maior a transparência de seus atos, e mais bem avaliados os entes públicos no requisito transparência, maior será a possibilidade de fiscalização, segurança e, consequentemente, confiança dos cidadãos nas ações desses gestores. O que difere esse estudo dos demais é a criação de uma nova escala, que mede a transparência ativa e a comparação com a escala criada pela Controladoria-Geral da União.

Diante do exposto, o presente artigo tem como objeto avaliar o grau de transparência ativa do processo de planejamento e execução orçamentária dos municípios de Mato Grosso do Sul, por meio do desenvolvimento de uma escala de avaliação, tendo como base as informações disponibilizadas nos seus sítios eletrônicos.

\section{FUNDAMENTAÇÃO TEÓRICA}

\subsection{Orçamento público}

O Orçamento Público é um instrumento de planejamento, em que se estabelece as políticas públicas prioritárias para o atendimento das demandas da sociedade, em face da escassez de recursos. Não se trata apenas de um mecanismo econômico, no qual são divididas as receitas e as despesas do Estado, mas de um instrumento que contém uma multiplicidade de aspectos, como: político, jurídico, administrativo, etc (Giacomoni, 2010).

O conceito de orçamento evoluiu ao longo do tempo, mas atualmente a definição desse instituto, segundo Giacomoni (2010), perpassa por duas fases: o orçamento tradicional e o orçamento moderno. O orçamento tradicional era tratado como mecanismo de controle político. Quando criado, o seu modelo adequava-se a ideia de liberalismo e a despesa pública era contida a ponto de não necessitar de maiores discussões acerca do tema, já que havia consciência de que o Estado 
deveria intervir cada vez menos. Isso fazia com que a despesa pública não aumentasse, somente mantivesse o mínimo necessário para o seu funcionamento. Dessa forma, a despesa pública, segundo Giacomoni (2010), era "um mal necessário".

Além dessa pequena preocupação com a questão econômica, outro aspecto que era considerado pelo orçamento tradicional era o jurídico, já que havia a discussão sobre o orçamento possuir ou não característica de lei ou de ato administrativo. Fato é que no orçamento tradicional não havia uma preocupação com classificações, como no orçamento moderno, resumindo-o à classificação por unidade administrativa e por objeto ou item de despesa.

Já no orçamento moderno, diferente do tradicional, Giacomoni (2010) aponta que a sua função principal é a de administração, pois possibilita ao gestor a programação, a execução e o controle das receitas e das despesas, inclusive na definição e na alocação de recursos para a consecução dos seus fins e da implementação de políticas públicas. Foi concomitante a esse modelo de orçamento que no Século XX passou-se a aderir a ideia de aliar orçamento e planejamento.

Assim, Lima e Castro (2011, p. 9) definem orçamento como:

O planejamento feito pela Administração Pública para atender, durante determinado período, os planos e programas de trabalho por ela desenvolvidos, por meio da planificação de receitas a serem obtidas e pelos dispêndios a serem efetuados, objetivando a continuidade e a melhoria quantitativa e qualitativa dos serviços prestados à sociedade.

A Constituição Federal de 1988 trata do tema no seu art. 165, em que estabelece legislações básicas para a elaboração do orçamento, sendo elas: o Plano Plurianual (PPA), as Diretrizes Orçamentárias (LDO) e os Orçamentos Anuais (LOA) (Brasil, 1988). Entender o papel dessas três legislações é de suma importância para que se possa analisar o que propõe o Governo e se este conseguiu atingir seus objetivos traçados no que se refere ao orçamento público. Tais leis fazem parte do que os estudiosos chamam de ciclo orçamentário (Sanches, 2006).

De acordo com o art. 165, inciso I, parágrafo primeiro da Constituição Federal de 1988, o Plano Plurianual "estabelecerá, de forma regionalizada, as diretrizes, objetivos e metas da administração pública federal para as despesas de capital e outras delas decorrentes e para as relativas aos programas de duração continuada". Por outro lado, para Garcia (2000), o PPA possui como principal objetivo possibilitar a coordenação das ações governamentais, subordinando os propósitos destas a todas as iniciativas do Estado.

Em âmbito Federal, o Decreto 2.829, 29 de outubro de 1998, que regulamenta a elaboração e execução do PPA da União, estabelece que este deverá ser 
estruturado em programas orientados a consecução dos objetivos estratégicos do governo (Brasil, 1998).

Com relação aos Municípios, enquanto não for editada a exigência do art. 165, § $9^{\circ}$, inc. I, da Constituição Federal, os prazos são os definidos no art. 35, $\S 2^{\circ}$, inc. I, ADCT, ou nas Leis Orgânicas dos Municípios (art. 22, caput, da LF 4.320/64).

Garcia (2000) aponta que nenhum investimento que ultrapassar o exercício financeiro para sua execução poderá ser iniciado sem inclusão no PPA ou lei que autorize essa inclusão, sob pena de crime de responsabilidade.

A lei de diretrizes orçamentárias encontra respaldo constitucional no art. 165, inciso II, parágrafo segundo, e tem por objetivo traçar as metas e as prioridades da Administração Pública, definindo parâmetros para a elaboração dos orçamentos fiscais, de seguridade social e de investimento (Brasil, 1988).

Já a lei orçamentária anual está prevista no art. 165, inciso III e sua composição prevista nos $\S \S 5^{\circ}, 6^{\circ}$ e $7^{\circ}$, desse mesmo artigo, da CF/88:

Art. 165. [...]

$\S 5^{\circ} \mathrm{A}$ lei orçamentária anual compreenderá:

I - O orçamento fiscal referente aos Poderes da União, seus fundos, órgãos e entidades da administração direta e indireta, inclusive fundações instituídas e mantidas pelo Poder Público;

II - O orçamento de investimento das empresas em que a União, direta ou indiretamente, detenha a maioria do capital social com direito a voto;

III - O orçamento da seguridade social, abrangendo todas as entidades e órgãos a ela vinculados, da administração direta ou indireta, bem como os fundos e fundações instituídos e mantidos pelo Poder Público.

$\S 6^{\circ} \mathrm{O}$ projeto de lei orçamentária será acompanhado de demonstrativo regionalizado do efeito, sobre as receitas e despesas, decorrente de isenções, anistias, remissões, subsídios e benefícios de natureza financeira, tributária e creditícia.

$\S 7^{\circ}$ Os orçamentos previstos no $\S 5^{\circ}$, I e II, deste artigo, compatibilizados com o plano plurianual, terão entre suas funções a de reduzir desigualdades inter-regionais, segundo critério populacional (Brasil, 1988).

Assim, na lei orçamentária anual deverá ser pormenorizada as receitas e despesas que serão realizadas pelo Governo no exercício da sua vigência.

As receitas podem ser conceituadas como o conjunto de meios financeiros que o Estado e as outras pessoas de direito público auferem, livremente, e sem reflexo no seu passivo, para custear a produção de seus serviços e executar as tarefas políticas dominantes em cada comunidade (Brasil, 2014).

Já as despesas, em sua acepção financeira, podem ser definidas como a 
aplicação de recursos pecuniários em forma de gastos e em forma de mutação patrimonial, com o fim de realizar as finalidades do Estado. Por outro lado, em sua acepção econômica, podem ser definidas como o gasto ou não de dinheiro para efetuar serviços tendentes àquelas finalidades (Brasil, 2014).

Dessa forma, é por meio do acompanhamento, do planejamento e da execução orçamentária que a sociedade poderá verificar se a aplicação dos recursos públicos está vindo ao encontro das suas necessidades, sendo a transparência de todo esse processo, condição essencial nesse propósito.

\subsection{Transparência, accountability e governo eletrônico}

A transparência pública é condição indispensável para o fortalecimento da democracia, sendo um dos pressupostos da boa governança. Slomski (2009) afirma que ao conduzir a gestão pública é preciso ter como pressupostos a transparência, a equidade, a prestação de contas (accountability) e a responsabilidade corporativa.

A transparência na administração pública é a intrínseca relação entre Estado e cidadão. A clareza e o fácil acesso a gestão dos recursos públicos são um estímulo a consciência ética e, em última instância, asseguram a accountability. Dessa forma, não se deve cultivar o dever de informar, mas sim o desejo de informar, para que se possa aumentar a proximidade entre Estado e sociedade. Tratando-se de prestação de contas, Slomski (2009) afirma que o cumprimento de tal princípio:

[...] é essencial não só com relatórios exigidos pela legislação, mas também com instrumentos que facilitem a transparência dos atos, de maneira espontânea, com relatórios que façam com que o cidadão possa fazer comparações com resultados privados e, assim, sentir-se confortável ao ver que a gestão pública está sendo eficiente nos gastos públicos, no curto prazo, haja vista que a eficácia dos atos da administração pública somente será perceptível a médio e longo prazo.

Assim, não basta não basta ter informações disponíveis, se elas não podem ser entendidas. A transparência não trata apenas da visibilidade das informações, mas também do modo como elas são dispostas. Em consequência disso, é preciso que ela conduza a inferências corretas (Angélico, 2012).

Dessa forma, apresenta-se a transparência ativa, ou seja, aquela que é disponibilizada de forma proativa, enquanto a passiva se constitui em canal de atendimento de informações solicitadas pelo cidadão. Um sistema transparente deve conter mecanismos de respostas e se a informação desejada não estiver disponível, o sistema deverá indicar onde e de que maneira o solicitante poderá acessar essa informação ou, simplesmente, entregar a informação ao solicitante (Angélico, 2012). 
A previsão legal sobre o tema evoluiu ao longo dos anos. Na Constituição Federal de 1988, encontra-se previsto no artigo $5^{\circ}, \mathrm{XXXIII}$, o direito de todos os cidadãos receberem informações dos entes públicos, sejam elas de seu interesse particular ou coletivo, com exceção para aquelas informações que são imprescindíveis à segurança da sociedade e do Estado.

Em 2000 entrou em vigor a Lei Complementar $n^{\circ} .101$ (Lei de Responsabilidade Fiscal - LRF) que estabeleceu normas para as finanças públicas e a responsabilidade na gestão fiscal, incluindo a divulgação, inclusive em meios eletrônicos de acesso ao público, dos planos, dos orçamentos, das leis de diretrizes orçamentárias, das prestações de contas acompanhadas do seu parecer prévio e dos relatórios de execução orçamentária e de gestão fiscal.

No ano de 2009 foi sancionada a Lei $n^{\circ} 131$, também conhecida como Lei da Transparência, que trouxe a obrigatoriedade da disponibilização de informações em tempo real sobre a execução orçamentária aos órgãos públicos.

Nesse caminho, em 2011 foi sancionada a Lei no. 12.527/2011 (Lei de Acesso a Informação - LAl), cujas diretrizes se encontram no seu artigo $3^{\circ}$, abaixo transcrito:

I - Observância da publicidade como preceito geral e do sigilo como exceção;

II - Divulgação de informações de interesse público, independentemente de solicitações;

III - Utilização de meios de comunicação viabilizados pela tecnologia da informação;

IV - Fomento ao desenvolvimento da cultura de transparência na administração pública;

V - Desenvolvimento do controle social da administração pública.

Desse modo, muitos são os dispositivos que tratam da disponibilização de informações pelos agentes públicos aos cidadãos quanto à arrecadação e aplicação dos recursos públicos em tempo real, cabendo a estes o exercício de acompanhamento e de cobrança por sanções, caso haja má aplicação desses recursos. Em outras palavras, cabe ao cidadão a prática da accountability.

No Brasil, o conceito de accountability é recente e não existe uma palavra em língua portuguesa que o traduza fielmente. Para Campos (1990), na cultura anglo-saxã o conceito diz respeito ao relacionamento entre a administração pública e seu público, remetendo-se à questão dos direitos dos cidadãos e à necessidade destes de garantir condutas adequadas na esfera pública.

Nesse contexto, a transparência é essencial para uma accountability efetiva, o que não se resume apenas na disponibilização de informações. É necessário que elas sejam de fácil entendimento e interpretação, para impulsionar o cidadão a monitorar e a avaliar todo o processo de planejamento e execução orçamentária. 
Assim, o governo eletrônico (e-government) assume papel de destaque. Abrucio (2007) afirma que o governo eletrônico, além de proporcionar transparência nos processos, deve promovê-la na execução de contratos e projetos, permitindo um acompanhamento em tempo real. $\mathrm{O}$ autor complementa, que essa ferramenta sozinha não é suficiente para uma accountability eficiente, é necessário que ela seja somada a um maior engajamento social.

A CGU editou o guia de implantação do portal da transparência que traz o conteúdo que deve ser disponibilizado no sítio eletrônico das prefeituras municipais, bem como a legislação de referência, conforme resumo constante no Quadro 1.

\section{Quadro 1 - Informações mínimas obrigatórias para implantação do portal da} transparência.

\begin{tabular}{|c|c|c|}
\hline \multicolumn{3}{|c|}{ SOBRE O CONTEÚDO } \\
\hline ASSUNTO & ORIENTAÇÃO & REFERÊNCIA \\
\hline \multicolumn{3}{|c|}{ DESPESA } \\
\hline Data da despesa & $\begin{array}{l}\text { A informação deve possibilitar o } \\
\text { acompanhamento da publicação } \\
\text { das despesas em tempo real. }\end{array}$ & $\begin{array}{l}\text { Decreto } \mathrm{n}^{\circ} 7.185 / 2010 \text { (Art. } \\
2^{\circ} \S 2^{\circ} \text { Inc. II) }\end{array}$ \\
\hline $\begin{array}{l}\text { Valor do empenho, liqui- } \\
\text { dação e pagamento }\end{array}$ & & $\begin{array}{l}\text { Decreto } n^{\circ} 7.185 / 2010 \text { (Art. } \\
7^{\circ} \text { Inc. I alínea a) }\end{array}$ \\
\hline $\begin{array}{l}\text { Número do processo de } \\
\text { execução }\end{array}$ & $\begin{array}{l}\text { Quando houver a possibilidade, de- } \\
\text { ve-se publicar essa informação. }\end{array}$ & $\begin{array}{l}\text { Decreto } n^{\circ} 7.185 / 2010 \text { (Art. } \\
7^{\circ} \text { Inc. I alínea b) } \\
\end{array}$ \\
\hline $\begin{array}{l}\text { Classificação orçamen- } \\
\text { tária }\end{array}$ & $\begin{array}{l}\text { A classificação orçamentária deve } \\
\text { especificar a unidade orçamentária, } \\
\text { a função, a subfunção, a natureza da } \\
\text { despesa e a fonte dos recursos que } \\
\text { financiaram o gasto. }\end{array}$ & $\begin{array}{l}\text { Decreto } n^{\circ} 7.185 / 2010 \text { (Art. } \\
7^{\circ} \text { Inc. I alínea c) }\end{array}$ \\
\hline $\begin{array}{l}\text { Identificação da Pessoa } \\
\text { Física ou Jurídica bene- } \\
\text { ficiária do pagamento }\end{array}$ & $\begin{array}{l}\text { A identificação do beneficiário deve } \\
\text { ocorrer inclusive nos desembolsos } \\
\text { de operações, independente da exe- } \\
\text { cução orçamentária. Recomenda- } \\
\text { se, além do nome ou razão social, } \\
\text { informar o CNPJ da pessoa jurídica } \\
\text { integralmente e o CPF da pessoa } \\
\text { física, ocultando os três primeiros dí- } \\
\text { gitos e os dois últimos dígitos. }\end{array}$ & $\begin{array}{l}\text { Decreto } \mathrm{n}^{\circ} 7.185 / 2010 \text { (Art. } \\
7^{\circ} \text { Inc. I alínea d) }\end{array}$ \\
\hline $\begin{array}{l}\text { Procedimento licitatório } \\
\text { realizado }\end{array}$ & $\begin{array}{l}\text { Divulgação do procedimento lici- } \\
\text { tatório, bem como, quando for o } \\
\text { caso, a sua dispensa ou inexigi- } \\
\text { bilidade com o número do corres- } \\
\text { pondente processo. }\end{array}$ & $\begin{array}{l}\text { Decreto } \mathrm{n}^{\circ} 7.185 / 2010 \text { (Art. } \\
7^{\circ} \text { Inc. I alínea e) }\end{array}$ \\
\hline $\begin{array}{l}\text { Descrição do bem forne- } \\
\text { cido ou do serviço pres- } \\
\text { tado }\end{array}$ & $\begin{array}{l}\text { Detalhamento do bem fornecido } \\
\text { ou serviço prestado. }\end{array}$ & $\begin{array}{l}\text { Decreto } n^{\circ} 7.185 / 2010 \text { (Art. } \\
7^{\circ} \text { Inc. I alínea f) }\end{array}$ \\
\hline Unidade gestora & & $\begin{array}{l}\text { Decreto } n^{\circ} 7.185 / 2010 \text { (Art. } \\
2^{\circ} \S 2^{\circ} \text { Inc. IV) }\end{array}$ \\
\hline
\end{tabular}




\begin{tabular}{|c|c|c|}
\hline \multicolumn{3}{|c|}{ DETALHAMENTO DA RECEITA } \\
\hline Data da posição & $\begin{array}{l}\text { Possibilita acompanhar a publica- } \\
\text { ção da receita em tempo real. }\end{array}$ & $\begin{array}{l}\text { Decreto } n^{\circ} 7.185 / 2010 \text { (Art. } \\
2^{\circ} \S 2^{\circ} \text { Inc. II) }\end{array}$ \\
\hline Unidade gestora & & $\begin{array}{l}\text { Decreto } \mathrm{n}^{\circ} 7.185 / 2010 \text { (Art. } \\
7^{\circ} \text {, Inc. II, caput) }\end{array}$ \\
\hline Natureza da receita & & $\begin{array}{l}\text { Decreto } \mathrm{n}^{\circ} 7.185 / 2010 \text { (Art. } \\
7^{\circ} \text {, Inc. II, caput) }\end{array}$ \\
\hline Valor da previsão & & $\begin{array}{l}\text { Decreto } n^{\circ} 7.185 / 2010 \text { (Art. } \\
7^{\circ} \text {, Inc. II, alínea a) }\end{array}$ \\
\hline Valor do lançamento & $\begin{array}{l}\text { Quando houver possibilidade, de- } \\
\text { ve-se publicar essa informação. }\end{array}$ & $\begin{array}{l}\text { Decreto } n^{\circ} 7.185 / 2010 \text { (Art. } \\
7^{\circ} \text {, Inc. II, alínea b) }\end{array}$ \\
\hline Valor da arrecadação & $\begin{array}{l}\text { Indica o valor da arrecadação, in- } \\
\text { clusive referente a recursos extra- } \\
\text { ordinários. }\end{array}$ & $\begin{array}{l}\text { Decreto } \mathrm{n}^{\circ} 7.185 / 2010 \text { (Art. } \\
7^{\circ}, \text { Inc. II, alínea c) }\end{array}$ \\
\hline \multicolumn{3}{|c|}{ Informações financeiras } \\
\hline Plano Plurianual (PPA) & Publicar versão simplificada. & Art. 48 LRF \\
\hline $\begin{array}{l}\text { Lei de diretrizes orça- } \\
\text { mentárias (LDO) }\end{array}$ & Publicar versão simplificada. & Art. $48 \mathrm{LRF}$ \\
\hline Prestação de contas & $\begin{array}{l}\text { A prestação de contas deve ser } \\
\text { acompanhada do parecer prévio } \\
\text { do Tribunal de Contas e de ver- } \\
\text { sões simplificadas. }\end{array}$ & Art. 48 LRF \\
\hline $\begin{array}{l}\text { Relatório resumido da } \\
\text { execução orçamentária } \\
\text { (RREO) }\end{array}$ & Publicar versão simplificada. & Art. $48 \mathrm{LRF}$ \\
\hline $\begin{array}{l}\text { Relatório de gestão fis- } \\
\text { cal (RGF) }\end{array}$ & Publicar versão simplificada. & Art. 48 LRF \\
\hline $\begin{array}{l}\text { Balanço anual do exer- } \\
\text { cício anterior }\end{array}$ & Publicar versão simplificada. & Art. $48 \mathrm{LRF}$ \\
\hline \multicolumn{3}{|c|}{ PROCEDIMENTOS LICITATÓRIOS } \\
\hline $\begin{array}{l}\text { Informações concer- } \\
\text { nentes a procedimento } \\
\text { licitatórios }\end{array}$ & $\begin{array}{l}\text { Publicação que contenha todas as } \\
\text { informações relativas a procedimen- } \\
\text { tos licitatórios, incluindo os respecti- } \\
\text { vos editais e resultados, bem como } \\
\text { a todos os contratos celebrados. }\end{array}$ & $\begin{array}{l}\text { Lei } 12.527 / 2011 \text { (Art. } 8^{\circ} \S 1^{\circ} \\
\text { Inc. IV) }\end{array}$ \\
\hline $\begin{array}{l}\text { Resumo dos instrumen- } \\
\text { tos de contrato ou de } \\
\text { seus aditivos e as co- } \\
\text { municações ratificadas } \\
\text { pela autoridade superior }\end{array}$ & & $\begin{array}{l}\text { - Lei 9.755/98 (Art. } 1^{\circ} \text { Inc. V); } \\
\text { (Art. } 26 \text { caput); (Art. } 61 \text { § único); } \\
\text { (Art. } 62 \S 3^{\circ} \text { ) } \\
\text { - Lei }{ }^{\circ} 8.666 / 93 \text { (Art. 116, 117, } \\
119 \text { e 124) }\end{array}$ \\
\hline $\begin{array}{l}\text { Relações Mensais de } \\
\text { todas as compras feitas } \\
\text { pela Administração dire- } \\
\text { ta e indireta }\end{array}$ & $\begin{array}{l}\text { Esta relação deve discriminar obri- } \\
\text { gatoriamente: a identificação do } \\
\text { bem comprado, seu preço unitário, } \\
\text { a quantidade adquirida, o nome do } \\
\text { vendedor e o valor total da opera- } \\
\text { ção, podendo ser aglutinadas por } \\
\text { itens as compras feitas com dis- } \\
\text { pensa e inexigibilidade de licitação. }\end{array}$ & $\begin{array}{l}\text { - Lei 9.755/98 (Art. } 1^{\circ} \text { Inc. VI) } \\
\text { - Lei 8.666/93 (Art. 16) }\end{array}$ \\
\hline
\end{tabular}

Fonte: Guia de implantação de portal da transparência (Brasil, 2013, p. 12-14) 
Nesse sentido, observou-se as informações contidas no guia para a realização da presente pesquisa, ou seja, a avaliação do grau de transparência ativa dos municípios sul-mato-grossenses.

\section{METODOLOGIA}

A fim de avaliar a transparência dos 79 (setenta e nove) municípios do Estado de Mato Grosso do Sul, realizou-se uma pesquisa descritiva, por meio de análise documental, com o auxílio de ferramentas quantitativas (Gil, 2002).

O Estado foi escolhido em razão de ter obtido uma das piores colocações $\left(23^{\mathrm{a}}\right)$ no último levantamento do Projeto Escala Brasil Transparente (EBT), bem como por tratar-se da região que abriga a instituição onde essa pesquisa foi desenvolvida.

O procedimento de coleta de dados pelos autores adotou as seguintes fases:

1. Definição dos eixos de transparência ativa a serem avaliados.

2. Definição dos quesitos avaliados dentro de cada eixo.

3. Estruturação do formulário de avaliação.

4. Coleta de dados, por meio de visita aos sítios eletrônicos das prefeituras.

5. Estruturação da base de dados.

6. Definição dos critérios de pontuação.

7. Inclusão de dados relacionados à população, volume de recursos e nota no último EBT na base de dados.

8. Análise dos dados.

Os eixos de transparência definidos no primeiro passo foram os seguintes: eixo de planejamento orçamentário, eixo de receitas, eixo de despesas e eixo de licitações. O eixo de planejamento orçamentário relaciona-se à transparência dos municípios, pela divulgação de instrumentos utilizados no planejamento da execução orçamentária, como o Plano Plurianual, a Lei de Diretrizes Orçamentárias e a Lei Orçamentária Anual. Os eixos de receitas e de despesas foram avaliados pela transparência que o município promove em relação às informações de arrecadação e dispêndio, respectivamente. O eixo de licitações trata-se da disponibilização de informações a respeito do procedimento de escolha do agente que contratará a administração.

O questionário (Anexo I) desenvolvido para a pesquisa permite duas respostas possíveis: não ou sim, sendo atribuído valor binário de 0 e 1, respectivamente, para fins de pontuação no Índice de Transparência Ativa (ITA), proposto por esse trabalho. 
Cada município obteve uma nota em uma escala de 0 a 10, resultante da soma dos 4 (quatro) eixos. A pontuação do eixo foi definida segundo a seguinte fórmula:

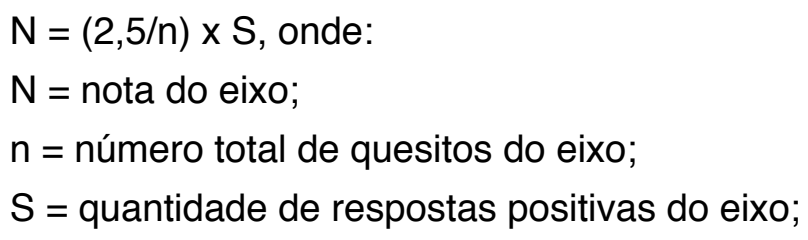

No passo 7, as informações a respeito da população foram obtidas junto à base de dados MUNIC, do Instituto Brasileiro de Geografia e Estatística (IBGE). Para as receitas e as despesas, foram utilizados os dados municipais de 2015, disponibilizados pela Secretaria do Tesouro Nacional (STN) e pela base de dados FINBRA. O ranking com as notas da edição 2015 da Escala Brasil Transparente (EBT) foi obtido junto ao site da Controladoria-Geral da União (CGU).

Realizados os passos de 1 a 7 , o resultado foi uma base de dados com as notas obtidas pelos 79 (setenta e nove) municípios de Mato Grosso do Sul, com informações sobre a população, as receitas e as despesas do ano de 2015 e nota no último EBT.

Com o intuito de analisar a base de dados, correlacionaram-se essas 4 (quatro) variáveis, com o auxílio do software ActionStat, versão 3.1.43.724.694. Primeiramente, verificou-se a hipótese de existir correlação significativa entre as notas obtidas em transparência ativa relacionada à população e às despesas orçamentárias dos municípios. Para tanto, utilizou-se o teste de correlação linear de Pearson. Em seguida, para a verificação da normalidade da distribuição das notas de transparência ativa e passiva (EBT), utilizou-se o teste de Kolmogorov - Smirnov (Costa Neto, 2002). Com isso, constatou-se que as notas de transparência passiva não apresentaram uma distribuição normal, apesar de as notas de transparência ativa seguirem uma distribuição normal.

Dado o resultado do teste anterior, optou-se pela utilização de um teste não paramétrico para observação de diferenças significativas entre as médias das notas de transparência ativa e passiva. O teste escolhido foi o de Wilcoxon para dados pareados (Fonseca; Martins, 2011).

Por fim, agrupou-se os municípios em estratos de acordo com sua população e suas despesas orçamentárias com as suas respectivas notas em transparência ativa. Como os estratos gerados para a população e para as despesas 
orçamentárias contavam com quantidade de municípios diferentes, utilizou-se o teste de Scheffé para verificar se as médias das notas de transparência ativa obtidas pelos municípios apresentavam diferença significativa entre os estratos (Conagin, 1959; Pimentel Gomes, 1990).

A análise do índice de transparência elaborado com as informações demográficas de receitas e de despesas teve como objetivo comparar se o volume da população impactada e o orçamento gerido pelo governo municipal influenciam no índice de transparência.

\section{RESULTADOS}

Ao todo, a presente pesquisa avaliou os 79 (setenta e nove) sítios eletrônicos dos municípios do estado de Mato Grosso do Sul.

\subsection{Ranking dos municípios}

Após avaliar os 79 (setenta e nove) municípios de Mato Grosso do Sul, suas notas foram colocadas em ordem decrescente e são apresentadas na Tabela 1.

Tabela 1: Ranking por município

\begin{tabular}{|c|c|c|c|c|c|}
\hline Ranking & Nota & Município & Ranking & Nota & Município \\
\hline $1^{\circ}$ & 9,38 & São Gabriel do Oeste & $41^{\circ}$ & 6,42 & Caarapó \\
\hline $2^{\circ}$ & 9,20 & Sonora & $42^{\circ}$ & 6,39 & Bataguassu \\
\hline $3^{\circ}$ & 9,14 & Nioaque & $43^{\circ}$ & 6,39 & Itaporã \\
\hline $4^{\circ}$ & 9,14 & Rochedo & $44^{\circ}$ & 6,33 & Jateí \\
\hline $5^{\circ}$ & 8,88 & Sidrolândia & $45^{\circ}$ & 6,19 & Nova Andradina \\
\hline $6^{\circ}$ & 8,59 & Santa Rita do Pardo & $46^{\circ}$ & 6,14 & Caracol \\
\hline $7^{\circ}$ & 8,56 & Taquarussu & $47^{\circ}$ & 6,09 & Paranhos \\
\hline $8^{\circ}$ & 8,52 & Rio Brilhante & $48^{\circ}$ & 6,04 & Três Lagoas \\
\hline $9^{\circ}$ & 8,46 & Terenos & $49^{\circ}$ & 5,93 & Ladário \\
\hline $10^{\circ}$ & 8,38 & Paraíso das Águas & $50^{\circ}$ & 5,65 & Anastácio \\
\hline $11^{\circ}$ & 8,28 & Japorã & $51^{\circ}$ & 5,39 & Jaraguari \\
\hline $12^{\circ}$ & 8,21 & Água Clara & $52^{\circ}$ & 5,33 & Itaquiraí \\
\hline $13^{\circ}$ & 8,08 & Cassilândia & $53^{\circ}$ & 5,20 & Mundo Novo \\
\hline $14^{\circ}$ & 8,03 & Pedro Gomes & $54^{\circ}$ & 5,16 & Alcinópolis \\
\hline $15^{\circ}$ & 8,01 & Amambai & $55^{\circ}$ & 5,04 & Ivinhema \\
\hline $16^{\circ}$ & 7,96 & Eldorado & $56^{\circ}$ & 4,79 & Aparecida do Taboado \\
\hline $17^{\circ}$ & 7,92 & Naviraí & $57^{\circ}$ & 4,77 & Costa Rica \\
\hline $18^{\circ}$ & 7,91 & Rio Negro & $58^{\circ}$ & 4,77 & Jardim \\
\hline $19^{\circ}$ & 7,83 & $\begin{array}{c}\text { Rio Verde de Mato } \\
\text { Grosso }\end{array}$ & $59^{\circ}$ & 4,46 & Paranaíba \\
\hline $20^{\circ}$ & 7,78 & Miranda & $60^{\circ}$ & 4,40 & Maracaju \\
\hline
\end{tabular}




\begin{tabular}{|c|c|c|c|c|c|}
\hline $21^{\circ}$ & 7,71 & Antônio João & $61^{\circ}$ & 4,39 & $\begin{array}{c}\text { Tacuru } \\
\text { continuação }\end{array}$ \\
\hline $22^{\circ}$ & 7,71 & Brasilândia & $62^{\circ}$ & 4,29 & Anaurilândia \\
\hline $23^{\circ}$ & 7,64 & Deodápolis & $63^{\circ}$ & 4,16 & Angélica \\
\hline $24^{\circ}$ & 7,50 & Camapuã & $64^{\circ}$ & 4,16 & Aquidauana \\
\hline $25^{\circ}$ & 7,50 & Vicentina & $65^{\circ}$ & 3,96 & Laguna Carapã \\
\hline $26^{\circ}$ & 7,47 & Dois Irmãos do Buriti & $66^{\circ}$ & 3,84 & Novo Horizonte do Sul \\
\hline $27^{\circ}$ & 7,46 & Coxim & $67^{\circ}$ & 3,79 & Juti \\
\hline $28^{\circ}$ & 7,27 & Selvíria & $68^{\circ}$ & 3,78 & Fátima do Sul \\
\hline $29^{\circ}$ & 7,25 & Chapadão do Sul & $69^{\circ}$ & 3,71 & Batayporã \\
\hline $30^{\circ}$ & 7,16 & Campo Grande & $70^{\circ}$ & 3,62 & Douradina \\
\hline $31^{\circ}$ & 7,07 & Ribas do Rio Pardo & $71^{\circ}$ & 3,54 & Aral Moreira \\
\hline $32^{\circ}$ & 6,96 & Inocência & $72^{\circ}$ & 3,54 & Bela Vista \\
\hline $33^{\circ}$ & 6,89 & Coronel Sapucaia & $73^{\circ}$ & 3,54 & Bonito \\
\hline $34^{\circ}$ & 6,89 & Dourados & $74^{\circ}$ & 2,86 & Guia Lopes da Laguna \\
\hline $35^{\circ}$ & 6,67 & Corumbá & $75^{\circ}$ & 2,18 & Corguinho \\
\hline $36^{\circ}$ & 6,64 & Bandeirantes & $76^{\circ}$ & 2,14 & Ponta Porã \\
\hline $37^{\circ}$ & 6,63 & Glória de Dourados & $77^{\circ}$ & 1,88 & Iguatemi \\
\hline $38^{\circ}$ & 6,58 & Sete Quedas & $78^{\circ}$ & 0,63 & Figueirão \\
\hline $39^{\circ}$ & 6,53 & Nova Alvorada do Sul & $79^{\circ}$ & 0,31 & Bodoquena \\
\hline $40^{\circ}$ & 6,53 & Porto Murtinho & & & \\
\hline
\end{tabular}

Fonte: Elaboração própria.

O município de São Gabriel do Oeste, com um orçamento de pouco mais de $\mathrm{R} \$ 120$ milhões e uma população de 22.203 habitantes, segundo dados do censo 2010, tem a gestão mais transparente de todo o estado. O município só não alcançou a nota máxima por não disponibilizar os dados do planejamento orçamentário para download e não divulgar a prestação de contas de anos anteriores.

O pior desempenho foi apresentado pelo município de Bodoquena, com um índice de transparência de 0,31 pontos. Apenas 4 (quatro) municípios obtiveram nota superior a 9,0, sendo que 2 (dois) obtiveram nota inferior a 1,0.

A Tabela 2 mostra a frequência de municípios de acordo com um intervalo de notas.

Tabela 2: Notas por frequência de municípios

\begin{tabular}{c|c|c}
\hline Nota & Número de Municípios & Municípios (\%) \\
\hline Até 2,00 & 3 & 3,80 \\
\hline $2,01-4,00$ & 12 & 15,19 \\
\hline $4,01-6,00$ & 16 & 20,25 \\
\hline $6,01-8,00$ & 33 & 41,77 \\
\hline $8,01-10,00$ & 15 & 18,99 \\
\hline Total & 79 & 100,00 \\
\hline
\end{tabular}

Fonte: Elaboração própria 


\subsection{Transparência por tamanho do orçamento e por população}

Segundo dados do ano de 2015 da Secretaria do Tesouro Nacional (FINBRA), o orçamento municipal dos municípios de MS é de pouco mais de $\mathrm{R} \$ 7,5$ bilhões. Portanto, um volume de recursos considerável é administrado pelos entes federativos locais.

Com a metodologia apresentada, faz-se necessário mensurar o nível de transparência da gestão municipal, considerando o volume de recursos administrados. A Figura 1 traz então as notas médias apresentadas dispostas em 6 (seis) faixas de orçamento.

Figura 1: Transparência por tamanho do Orçamento

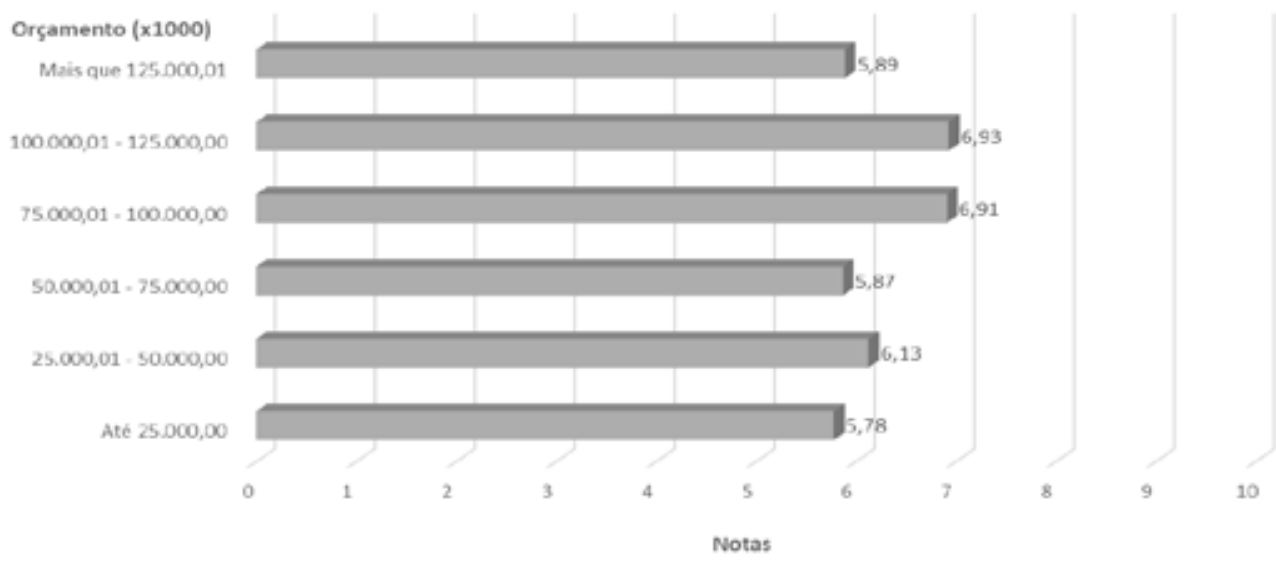

Fonte: Elaboração própria.

Os 4 (quatro) maiores orçamentos do estado, composto pelas cidades de Campo Grande, Dourados, Três Lagoas e Corumbá, totalizam R\$ 3,9 bilhões, representando $52 \%$ do orçamento total dos municípios. A nota média dessas 4 (quatro) cidades foi de 6,69.

Os níveis de transparência também foram analisados sob a perspectiva populacional dos municípios. O objetivo é avaliar quantos cidadãos tem acesso às informações de seu município, frente a população total do estado (1.972.743 habitantes). A Figura 2 traz então as notas médias apresentadas dispostas em 6 (seis) faixas populacionais. 
Figura 2: Transparência por população

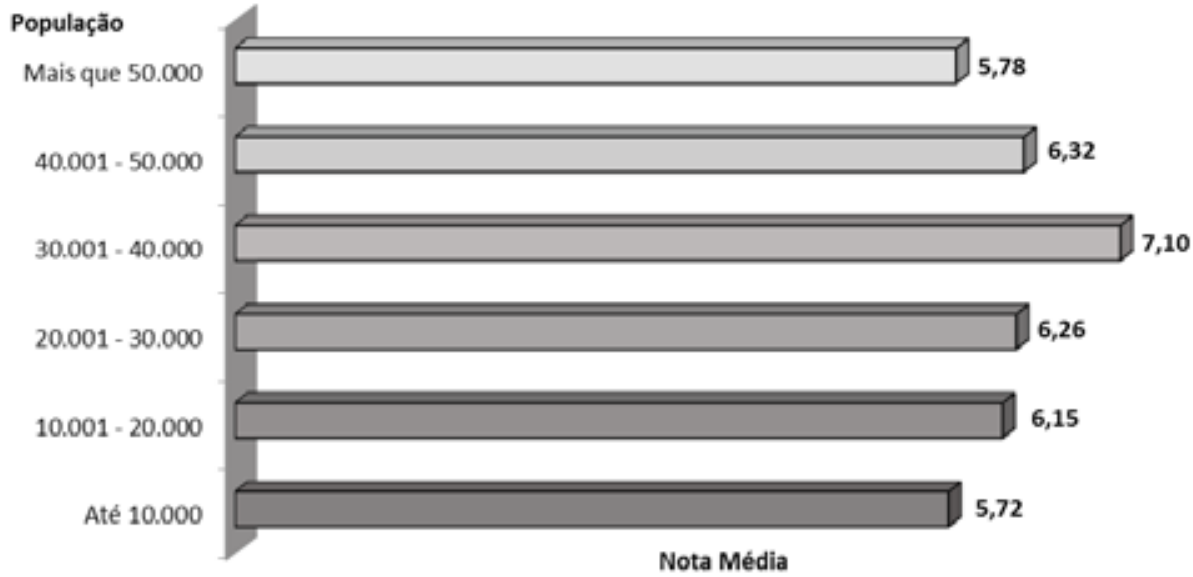

Fonte: Elaboração própria.

Viu-se anteriormente que as 4 (quatro) maiores cidades (Campo Grande, Dourados, Três Lagoas e Corumbá) obtiveram uma pontuação de 6,69. Somados, esses municípios possuem uma população de 1.188 .326 habitantes, ou seja, $60,2 \%$ da população tem acesso a uma quantidade razoável de informações da gestão municipal.

Os Quadros 2 e 3 trazem o resultado da correlação linear de Pearson entre as notas dos municípios e duas variáveis: população e despesas.

\section{Quadro 2 - Matriz de correlação de população e nota} Matriz de Correlação

\begin{tabular}{|c|c|c|}
\hline & \multicolumn{3}{|c|}{ Matriz de Correlação } \\
\hline & População & Nota \\
\hline $\begin{array}{c}\text { População } \\
\text { Nota }\end{array}$ & 1 & 0,068990605 \\
\hline & 0,068990605 & 1 \\
\hline & Matriz de P-Valores & \\
\hline População & População & Nota \\
\hline Nota & 1 & 0,548381631 \\
\hline
\end{tabular}

Fonte: Elaborado pelos autores.

Quadro 3 - Matriz de Correlação

Matriz de Correlação

Despesas Nota

\begin{tabular}{c|c|c|}
\hline Despesas & 1 & 0,070271986 \\
\hline Nota & 0,070271986 & 1 \\
\hline & Matriz de P-Valores & Nota \\
\hline
\end{tabular}


Caio Luis Chiariello, Felipe Ferreira Paulucio, Ricardo França de Brito Gisele de Souza Assumpção, Morrison Francisco Reis Verão, João Batista de Morais

\section{Despesas}

Nota

Fonte: Elaborado pelos autores.
1

0,554672984

\section{0,554672984}

1

Com o teste de Pearson, verificou-se a inexistência de uma correlação significativa entre as notas obtidas em transparência ativa relacionadas à população dos municípios e entre as notas e as despesas orçamentárias. Ademais, notou-se que as médias das notas obtidas pelos municípios entre os estratos são iguais estatisticamente, com 5\% de significância, pelo teste de Scheffé. Em outras palavras, não se observaram diferenças estatisticamente significativas entre as notas obtidas pelos municípios e sua população, nem entre suas notas e suas despesas orçamentárias.

\subsection{Comparação com as notas do último levantamento do Escala Brasil Transparente (EBT)}

Para efeito de comparação, a Tabela 3 estabelece um paralelo entre as notas obtidas pelos municípios participantes da última edição do projeto Escala Brasil Transparente (EBT) e o Índice de Transparência Ativa (ITA) adotado nesse trabalho.

É importante salientar que dos 79 (setenta e nove) municípios de Mato Grosso do Sul, apenas 40 (quarenta) se inscreveram para avaliação no EBT.

Tabela 3 - Comparativo EBT e ITA

\begin{tabular}{c|c|c|c|c|c}
\hline Municípios & $\begin{array}{c}\text { Transp. } \\
\text { Passiva } \\
\text { (EBT) }\end{array}$ & $\begin{array}{c}\text { Transp. } \\
\text { Ativa } \\
\text { (ITA) }\end{array}$ & Municípios & $\begin{array}{c}\text { Transp. } \\
\text { Passiva } \\
\text { (EBT) }\end{array}$ & $\begin{array}{c}\text { Transp. } \\
\text { Ativa } \\
\text { (ITA) }\end{array}$ \\
\hline Inocência & 10 & 6,96 & Jateí & 1,39 & 6,33 \\
\hline Ladário & 8,19 & 5,93 & Antônio João & 0,56 & 7,71 \\
\hline Nova Andradina & 7,92 & 6,19 & Douradina & 0,56 & 3,62 \\
\hline Campo Grande & 6,81 & 7,16 & Jaraguari & 0,56 & 5,39 \\
\hline Aparecida do Taboado & 6,67 & 4,79 & Sete Quedas & 0,56 & 6,58 \\
\hline Corguinho & 6,39 & 2,18 & Alcinópolis & 0 & 5,16 \\
\hline Terenos & 6,11 & 8,46 & Bataguassu & 0 & 6,39 \\
\hline Costa Rica & 5,42 & 4,77 & Bonito & 0 & 3,54 \\
\hline Sidrolândia & 4,86 & 8,88 & Brasilândia & 0 & 7,71 \\
\hline Pedro Gomes & 4,58 & 8,03 & Dourados & 0 & 6,89 \\
\hline Camapuã & 4,31 & 7,50 & Laguna Carapã & 0 & 3,96 \\
\hline Guia Lopes da Laguna & 4,31 & 2,86 & Maracaju & 0 & 4,40 \\
\hline
\end{tabular}




\begin{tabular}{|c|c|c|c|c|c|}
\hline Iguatemi & 4,17 & 1,88 & Miranda & 0 & 7,78 \\
\hline Água Clara & 3,06 & 8,21 & Mundo Novo & 0 & 5,20 \\
\hline Angélica & 2,78 & 4,16 & Nioaque & 0 & 9,14 \\
\hline Naviraí & 2,78 & 7,92 & $\begin{array}{l}\text { Nova Alvorada } \\
\text { do Sul }\end{array}$ & 0 & 6,53 \\
\hline Fátima do Sul & 1,94 & 3,78 & $\begin{array}{l}\text { Paraíso das } \\
\text { Águas }\end{array}$ & 0 & 8,38 \\
\hline Taquarussu & 1,94 & 8,56 & Paranaíba & 0 & 4,46 \\
\hline São Gabriel do Oeste & 1,67 & 9,38 & Porto Murtinho & 0 & 6,53 \\
\hline Japorã & 1,39 & 8,28 & Sonora & 0 & 9,20 \\
\hline \multicolumn{2}{|c|}{ 1Média transparência ativa } & $6,27 \mathrm{a}$ & \multicolumn{2}{|c|}{$\begin{array}{c}\text { Média transparência } \\
\text { passiva }\end{array}$} & $2,47 \mathrm{~b}$ \\
\hline
\end{tabular}

Fonte: Elaboração própria

O município mais bem avaliado no EBT foi Inocência, com nota 10. No ITA, sua nota foi de 6,96 , tendo em vista não ter atendido a 5 (cinco) itens do eixo de planejamento orçamentário, 2 (dois) itens do eixo de receita e 2 (dois) itens do eixo de despesa. A menor nota no ITA entre os 40 (quarenta) municípios avaliados pelas duas escalas foi de 1,88 (Iguatemi) e dos que participaram da última edição do EBT avaliados nesse trabalho, o município que obteve maior índice ITA foi Nioaque com 9,14.

Cumpre referir que, embora tenham se inscrito para a participação na Escala Brasil Transparente, 15 (quinze), ou seja, 38\% dos municípios participantes apresentaram nota zero na avaliação. Fato que influenciou significativamente o resultado. Desconsiderados esses que não alcançaram qualquer pontuação, a média da transparência passiva passaria para 3,95, melhorando assim o resultado da transparência passiva.

Tabela 4 - Estatística do Teste (Wilcoxon)

\begin{tabular}{cc}
\hline Informações & Valores \\
\hline Estatística & 64 \\
\hline P-valor & 0 \\
\hline Hipótese Nula & 0 \\
\hline Limite Inferior & $-5,32320124$ \\
\hline (Pseudo) Mediana & $-4,123163368$ \\
\hline Limite Superior & $-2,584822423$ \\
\hline Nível de Confiança & 0,95 \\
\hline
\end{tabular}

Fonte: Elaboração própria 
De acordo com o teste de Wilcoxon para dados pareados, existem evidências de 95\% de significância que as médias obtidas em transparência passiva para os municípios que participaram da avaliação da Escala Brasil Transparente sejam diferentes da média obtida pelos mesmos municípios na avaliação da transparência ativa. Logo, ainda que desconsideradas as notas zeradas da EBT, esses municípios apresentam uma melhor transparência ativa que passiva.

É importante ressaltar que há um lapso temporal entre a realização das duas pesquisas. Enquanto a avaliação do EBT se deu entre 07/2015 e 10/2015, o ITA foi avaliado no mês 11/2016. Portanto, é compreensível que municípios com notas baixas no EBT tenham tido um desempenho melhor no ITA, já que a avaliação feita pela Controladoria-Geral da União os alertou para o quesito transparência de informações.

\section{CONSIDERAÇÕES FINAIS}

A prestação de contas por parte dos governantes é tema recorrente e essencial ao seguimento do conturbado pacto social que entremeia o desenvolvimento da sociedade desde seus primórdios. Os mecanismos e os instrumentos de controle da sociedade civil para com seus governantes devem ser ampliados e viabilizados de tal forma que possam promover o debate e a participação social no curso dos gastos e da arrecadação dos entes públicos.

Da maneira acelerada que a velocidade da informação cresce, concomitante com as facilidades de acesso promovidas pela expansão da internet, não há como omitir informações que são de direito dos cidadãos. Surge assim, a necessidade dos entes públicos buscarem formas de disponibilizar informações de fácil entendimento e interpretação para a população, aprimorando a accountability.

A transparência no ato público pode evidenciar tanto uma má gestão como também uma insuficiência na arrecadação, podendo ser determinante para definir o tamanho da intervenção necessária por parte do Estado.

A partir dos resultados apresentados, observa-se que não há uma diferença significativa da transparência ativa de acordo com a população ou com o montante de despesas dos municípios. Ademais, apesar de 41,17\% dos municípios terem apresentado notas entre 6,0 e 8,0, 39,24\% dos municípios de Mato Grosso do Sul obtiveram desempenho inferior a 6,0.

É válido destacar que a grande maioria dos municípios não conseguiram cumprir os requisitos da transparência passiva medida pela EBT. No total foram 15 municípios, ou seja, 38\% dos municípios avaliados tiraram nota zero. 
Ao comparar os índices de transparência passiva (EBT) e transparência ativa (ITA), verifica-se uma maior maturidade dos municípios quanto à transparência ativa. Tal fato pode ser atribuído a existente padronização das informações a serem disponibilizadas. Porém, quanto ao atendimento às solicitações de informações provocadas pelos cidadãos ou por órgãos de controle, ainda há dificuldade para atender a esses pedidos.

Cumpre referir que devido ao lapso temporal entre a realização das duas pesquisas, o desempenho dos municípios avaliados pelo EBT foi inferior ao ITA. Assim, pode-se concluir que embora a maioria dos municípios do estado de Mato Grosso do Sul ainda apresentem taxas de transparência incipientes, houve uma evolução na promoção da transparência pelos entes pesquisados.

Por fim, é interessante ressaltar a importância da criação de instrumentos objetivos para a avaliação e a medição dos aspectos relacionados à promoção da transparência pelos órgãos públicos. Escalas como o EBT e o ITA elaboradas nesse trabalho, permitem ao público avaliar a gestão de seus governantes e a preocupação desses em prestar conta de suas ações aos seus administradores.

\section{REFERÊNCIAS}

Angélico, Fabiano. (2012). Lei de Acesso à Informação Pública e seus possíveis desdobramentos para a accountability democrática no Brasil. 133 f. Dissertação (CMAPG) - Escola de Administração de Empresas de São Paulo.

Abrucio, F. L.; Loureiro, M. R. (2004) Finanças Públicas, Democracia e Accountability. In: Arvate, P. R.; Biderman, C. Economia do Setor Público no Brasil Rio de Janeiro: Elsevier/CAMPUS.

Abrucio, F. L. (2007). Trajetória recente da gestão brasileira: um balanço crítico e a renovação da agenda de reformas. Revista de Administração Pública. [Ed. Especial], 67-86.

Brasil. (1988). Constituição da República Federativa do Brasil de 1988. Brasília: Senado Federal. Recuperado de: <http://www.planalto.gov.br/ccivil_03/ Constituicao/Constituicao.htm>

Decreto $n^{\circ} 2.829$, de 29 de outubro de 1998. Estabelece normas para a elaboração e execução do Plano Plurianual e dos Orçamentos da União, e dá outras providências. Recuperado de: <http://www.planalto.gov.br/cci- 
vil_03/decreto/D2829.htm>.

Lei $n^{\circ}$. 12.527, de 18 de novembro de 2011. Regula o acesso a informações previsto no inciso XXXIII do art. $5^{\circ}$, no inciso II do $\S 3^{\circ}$ do art. $37 \mathrm{e}$ no $\S 2^{\circ}$ do art. 216 da Constituição Federal; altera a Lei $n^{\circ} 8.112$, de 11 de dezembro de 1990; revoga a Lei $n^{\circ} 11.111$, de 5 de maio de 2005, e dispositivos da Lei $n^{\circ} 8.159$, de 8 de janeiro de 1991; e dá outras providências. Recuperado de: <http://www.planalto.gov.br/ccivil_03/_ato2011-2014/2011/ lei/l12527.htm>.

Lei $n^{\circ}$. 4320, de 17 de março de 1964. Estatui Normas Gerais de Direito Financeiro para elaboração e controle dos orçamentos e balanços da União, dos Estados, dos Municípios e do Distrito Federal. Recuperado de: <https:// www.planalto.gov.br/ccivil_03/leis/L4320.htm>.

Controladoria Geral da União (2011). Acesso à Informação Pública: Controladoria-Geral da União Uma introdução à Lei $n^{\circ}$ 12.527, de 18 de novembro de 2011. Brasília: Eclips Design. Recuperado de: <http://www. saocarlos.sp.gov.br/images/stories/pdf/CartilhaAcessoalnform-acao.pdf>

Controladoria Geral da União (2016.). Escala Brasil Transparente: Ministério da Transparência, Fiscalização e Controladoria-Geral da União. Recuperado de: http://www.cgu.gov.br/assuntos/transparencia-publica/ escala-brasil-transparente/escala-brasil-transparente.

Controladoria Geral da União (2013). GUIA de implantação de Portal da Transparência. Brasília. Recuperado de: <http://www.cgu.gov.br/Publicacoes/transparenciapublica/brasiltransparente/arquivos/guia_portaltransparencia.pdfs.

BRASIL. (2014) Secretaria do Tesouro Nacional. Manual de Contabilidade Aplicada ao Setor Público. (6. ed). Brasília: STN.

Brasil. (2016). Secretaria do Tesouro Nacional. FINBRA - Finanças do Brasil - Dados Contábeis dos Municípios . Recuperado de: <http://www.tesouro.fazenda.gov.br/pt_PT/contas-anuais>.

Campos, A. M. (1990). Accountability: quando poderemos traduzi-la para o português?. Revista de Administração Pública, 24(2), 30-50.

Campos, R.; Paiva, D.; Gomes, S. (2013). Gestão da Informação Pública: um estudo sobre o portal da transparência. Soc. Estado, 28(2).

Ceneviva, R.; Farah, M. F. S. (2006). Democracia, avaliação e accountability: a avaliação de políticas públicas como instrumento de controle democrático. In: Encontro de Administração Pública e Governança da ANPAD. São Paulo: 


\section{EnAPG ANPAD.}

Conagin, A. (1959). Testes modernos para a comparação de médias. Bragantina [online], vol. 18. Recuperado de: <http://www.scielo.br/pdf/brag/v18nunico/01.pdfs.

Costa, Neto P. L. O. (2002). Estatística. (2. ed). São Paulo: Edgard Blucher.

Cruz, C. F.; Ferreira, A. C. S.; Silva, L. M.; Macedo, M. Á. S. (2012). Transparência da Gestão Pública Municipal: Um Estudo a partir dos Portais Eletrônicos dos Maiores Municípios Brasileiros. Rev. Administração Pública, 46(1). Recuperado de: < http://bibliotecadigital.fgv.br/ojs/index.php/rap/article/ view/7080/5635>.

Fonseca, J. S.; Martins, G. A. M. (2011). Curso De Estatística. (ed. 6). São Paulo: Atlas.

Garcia, Ronaldo C. (2000). A Reorganização Do Processo De Planejamento Do Governo Federal: O PPA 2000-2003. Brasília: IPEA.

Gil, A.C. (2002). Como Elaborar Projetos De Pesquisa. São Paulo: Atlas.

Giacomoni, James. (2010). Orçamento Público. (15. ed). São Paulo: Atlas S.A.

Lima, D. V.; Castro, R. G. (2011). Contabilidade Pública: integrando União, Estados e Municípios. (3 ed). São Paulo: Atlas

O'donnell, G. (1998). Accountability Horizontal E Novas Poliarquias. Lua Nova: Revista de Cultura e Política, $\mathrm{n}^{\circ} 44$.

Pimentel, Gomes F. (1990). Curso De Estatística Experimental. (13. ed). Piracicaba - SP: Editora da Universidade de São Paulo

Sanches, Osvaldo Maldonado. (2006). Planejamento E Orçamento Governamental; coletânea / vol. 2, cap. 3. Organizadores: James Giacomoni e José Luiz Pagnussat. Brasília: ENAP.

Slomsky, V. (2009) Controladoria E Governança Na Gestão Pública. (3. ed). São Paulo: Atlas. 


\section{ANEXOS}

Anexo I - Questionário Base de Dados para Pesquisa

\begin{tabular}{|c|c|c|}
\hline ITENS & PERGUNTAS & \\
\hline 1 & A Prefeitura possui sítio eletrônico? & \\
\hline 1.1 & $\begin{array}{c}\text { Existe link para o Portal da Transparência na página } \\
\text { inicial do site da Prefeitura Municipal? }\end{array}$ & \\
\hline 2 & \begin{tabular}{|l|} 
ORÇAMENTO ESTIMADO \\
\end{tabular} & BASE LEGAL \\
\hline 2.1 & $\begin{array}{l}\text { Existe link disponível de fácil acesso na página que leva } \\
\text { ao Plano Plurianual (PPA), mesmo em versão simplifica- } \\
\text { da? Considera-se fácil acesso a necessidade de clicar } \\
\text { em no máximo } 2 \text { links. }\end{array}$ & Art. 48 da LRF \\
\hline 2.2 & $\begin{array}{l}\text { Existe link disponível de fácil acesso na página que leva à } \\
\text { Lei de Diretrizes Orçamentárias (LDO), mesmo em versão } \\
\text { simplificada? Considera-se fácil acesso a necessidade de } \\
\text { clicar em no máximo } 2 \text { links. }\end{array}$ & Art. 48 da LRF \\
\hline 2.3 & $\begin{array}{l}\text { Existe link disponível de fácil acesso na página que leva } \\
\text { à Lei Orçamentária Anual (LOA), mesmo em versão sim- } \\
\text { plificada? Considera-se fácil acesso a necessidade de } \\
\text { clicar em no máximo } 2 \text { links. }\end{array}$ & Art. 48 da LRF \\
\hline 2.4 & $\begin{array}{l}\text { É possível fazer download dos dados do orçamento na } \\
\text { forma de planilha eletrônica? }\end{array}$ & \\
\hline 2.5 & $\begin{array}{l}\text { Está disponível no site a Prestação de Contas acompa- } \\
\text { nhada do Parecer do Tribunal de Contas da União dos } \\
\text { anos anteriores? }\end{array}$ & Art. 48 LRF \\
\hline 2.6 & $\begin{array}{l}\text { Está disponível no site a Relatório Resumido da Execu- } \\
\text { ção Orçamentária (RREO)? }\end{array}$ & Art. 48 LRF \\
\hline 2.7 & Está disponível no site a Relatório de Gestão Fiscal (RGF)? & Art. 48 LRF \\
\hline 2.8 & $\begin{array}{l}\text { Está disponível no site a Balanço Anual do Exercício } \\
\text { Anterior? }\end{array}$ & $\begin{array}{l}\text { Lei 9.755/98 (Art. } 1^{\circ} \\
\text { Inciso IV) }\end{array}$ \\
\hline 3 & RECEITA REAL & BASE LEGAL \\
\hline 3.1 & A receita ORÇADA e REALIZADA está publicada no site? & \\
\hline \multirow[t]{2}{*}{3.2} & $\begin{array}{l}\text { As INFORMAÇÕES DA RECEITA estão disponibilizadas } \\
\text { em tempo real? Liberação em tempo real: a disponibilização } \\
\text { das informações, em meio eletrônico que possibilite amplo } \\
\text { acesso público, até o primeiro dia útil subsequente à data } \\
\text { do registro contábil no respectivo SISTEMA, sem prejuízo } \\
\text { do desempenho e da preservação das rotinas de segurança } \\
\text { operacional necessários ao seu pleno funcionamento; }\end{array}$ & $\begin{array}{l}\text { Decreto } \mathrm{n}^{\circ} \\
\text { 7.185/2010 (Art. } 2^{\circ} \\
\S 2^{\circ} \text { Inc. II) }\end{array}$ \\
\hline & $\begin{array}{l}\text { A receita está detalhada com os seguintes requisitos, } \\
\text { mesmo que através da utilização de filtros: }\end{array}$ & \\
\hline 3.3 & Data da posição & $\begin{array}{c}\text { Decreto } \mathrm{n}^{\circ} \\
\text { 7.185/2010 (Art. } 2^{\circ} \\
\S 2^{\circ} \text { Inc. II) }\end{array}$ \\
\hline 3.4 & Valor da previsão & $\begin{array}{l}\text { Decreto } n^{\circ} \\
\text { 7.185/2010 (Art. } 7^{\circ} \\
\text { Inc. II alínea a) }\end{array}$ \\
\hline
\end{tabular}




\begin{tabular}{|c|c|c|}
\hline 3.5 & Valor da arrecadação/lançamento & $\begin{array}{l}\text { Decreto } \mathrm{n}^{\circ} \\
\text { 7.185/2010 (Art. } 7^{\circ} \\
\text { Inc. II alínea b) }\end{array}$ \\
\hline 3.6 & $\begin{array}{l}\text { A receita realizada está detalhada por CATEGORIA } \\
\text { ECONÔMICA? }\end{array}$ & $\begin{array}{l}\text { Decreto } \mathrm{n}^{\circ} \\
\text { 7.185/2010 (Art. } 7^{\circ} \\
\text { Inc. II alínea a) }\end{array}$ \\
\hline 3.7 & $\begin{array}{l}\text { A receita realizada está detalhada por GRUPOS DE } \\
\text { FONTES? }\end{array}$ & $\begin{array}{l}\text { Decreto } \mathrm{n}^{\circ} \\
\text { 7.185/2010 (Art. } 7^{\circ} \\
\text { Inc. II alínea a) }\end{array}$ \\
\hline 3.8 & $\begin{array}{l}\text { A receita realizada está detalhada por FONTES DE RE- } \\
\text { CURSOS? }\end{array}$ & $\begin{array}{l}\text { Decreto } \mathrm{n}^{\circ} \\
\text { 7.185/2010 (Art. } 7^{\circ} \\
\text { Inc. II alínea a) }\end{array}$ \\
\hline 3.9 & $\begin{array}{l}\text { A receita realizada está detalhada por CLASSIFICAÇÃO } \\
\text { INSTITUCIONAL? }\end{array}$ & $\begin{array}{l}\text { Decreto } \mathrm{n}^{\circ} \\
7.185 / 2010 \text { (Art. } 7^{\circ} \\
\text { Inc. II caput) }\end{array}$ \\
\hline 3.10 & $\begin{array}{l}\text { É possível fazer download dos dados das receitas no for- } \\
\text { mato de planilha eletrônica? }\end{array}$ & \\
\hline 4 & DESPESA REAL & BASE LEGAL \\
\hline 4.1 & A despesa ORÇADA e REALIZADA está publicada no site? & \\
\hline \multirow[t]{2}{*}{4.2} & \multicolumn{2}{|c|}{$\begin{array}{l}\text { As INFORMAÇÕES DA DESPESA estão disponibilizadas em tempo real? Libera- } \\
\text { ção em tempo real: a disponibilização das informações, em meio eletrônico que pos- } \\
\text { sibilite amplo acesso público, até o primeiro dia útil subsequente à data do registro } \\
\text { contábil no respectivo SISTEMA, sem prejuízo do desempenho e da preservação } \\
\text { das rotinas de segurança operacional necessários ao seu pleno funcionamento; }\end{array}$} \\
\hline & A despesa está detalhada com os seguintes requisitos: & \\
\hline 4.3 & Data da despesa & $\begin{array}{l}\text { Decreto } \mathrm{n}^{\circ} \\
7.185 / 2010 \text { (Art. } 2^{\circ} \\
\S 2^{\circ} \text { Inc. II) }\end{array}$ \\
\hline 4.4 & Valor do empenho, liquidação e pagamento & $\begin{array}{l}\text { Decreto } \mathrm{n}^{\circ} \\
\text { 7.185/2010 (Art. } 7^{\circ} \\
\text { Inc. I alínea a) }\end{array}$ \\
\hline 4.5 & $\mathrm{~N}^{\circ}$ do processo de execução & $\begin{array}{l}\text { Decreto } \mathrm{n}^{\circ} \\
7.185 / 2010 \\
\text { (Art. } 7^{\circ} \text { Inc. I alínea b) }\end{array}$ \\
\hline 4.6 & $\mathrm{~N}^{\circ}$ da Licitação & $\begin{array}{l}\text { Decreto } \mathrm{n}^{\circ} \\
\text { 7.185/2010 (Art. } 7^{\circ} \\
\text { Inc. I alínea e) }\end{array}$ \\
\hline 4.7 & $\begin{array}{l}\text { Identificação da pessoa física ou jurídica beneficiária do } \\
\text { pagamento }\end{array}$ & $\begin{array}{l}\text { Decreto } \mathrm{n}^{\circ} \\
7.185 / 2010\left(\text { Art. } 7^{\circ}\right. \\
\text { Inc. I alínea d) }\end{array}$ \\
\hline 4.8 & Detalhamento do bem e/ou serviço fornecido? & $\begin{array}{l}\text { Decreto } \mathrm{n}^{\circ} \\
7.185 / 2010 \text { (Art. } 7^{\circ} \\
\text { Inc. I alínea f) }\end{array}$ \\
\hline 4.9 & $\begin{array}{l}\text { A despesa realizada está disponível por CLASSIFICA- } \\
\text { ÇÃO INSTITUCIONAL? }\end{array}$ & $\begin{array}{l}\text { Decreto } \mathrm{n}^{\circ} \\
7.185 / 2010 \\
\text { (Art. } 7^{\circ} \text { Inc. I alínea c) }\end{array}$ \\
\hline 4.10 & $\begin{array}{l}\text { A despesa realizada está disponível por CLASSIFICA- } \\
\text { ÇÃO FUNCIONAL? }\end{array}$ & $\begin{array}{l}\text { Decreto } \mathrm{n}^{\circ} \\
7.185 / 2010 \\
\text { (Art. } 7^{\circ} \text { Inc. I alínea c) }\end{array}$ \\
\hline
\end{tabular}




\begin{tabular}{|c|c|c|}
\hline 4.11 & $\begin{array}{l}\text { A despesa realizada está disponível por CLASSIFICA- } \\
\text { ÇÃO POR PROGRAMAS? }\end{array}$ & $\begin{array}{l}\text { Art. } 2^{\circ} \text { da Portaria } \\
42 / 99\end{array}$ \\
\hline 4.12 & $\begin{array}{l}\text { A despesa realizada está disponível por CLASSIFICA- } \\
\text { ÇÃO POR NATUREZA, detalhado até o nível de sube- } \\
\text { lemento? }\end{array}$ & $\begin{array}{c}\text { Decreto } \mathrm{n}^{\circ} \\
7.185 / 2010 \\
\text { (Art. } 7^{\circ} \text { Inc. I alínea c) }\end{array}$ \\
\hline 4.13 & $\begin{array}{l}\text { É possível fazer download dos dados das despesas no } \\
\text { formato de planilha eletrônica? }\end{array}$ & \\
\hline 4.14 & $\begin{array}{l}\text { É fornecida a relação de servidores (concursados e ocu- } \\
\text { pantes de cargos comissionados) com os valores da re- } \\
\text { muneração? }\end{array}$ & $\begin{array}{l}\text { Art. } 7^{\circ} \text { e } 8^{\circ} \text { da Lei } \\
12527 / 2011 \text { e inciso } \\
\text { VI do art. } 7^{\circ} \text { do } \\
\text { Decreto } 7724 / 2012 \\
\end{array}$ \\
\hline 5 & LICITAÇÕES & BASE LEGAL \\
\hline 5.1 & $\begin{array}{l}\text { A prefeitura publica os instrumentos convocatórios (ex. } \\
\text { editais completos) de seus processos licitatórios? }\end{array}$ & $\begin{array}{c}\text { Lei } 12.527 / 2011 \\
\text { (Art. } 8^{\circ} \S 1^{\circ} \text { Inciso } \\
\text { IV) c/c princípio da } \\
\text { publicidade da Lei } \\
8666 / 93\end{array}$ \\
\hline 5.2 & $\begin{array}{l}\text { A prefeitura divulga o resultado final dos procedimentos } \\
\text { licitatórios, com o nome, CNPJ e valor por vencedor? }\end{array}$ & $\begin{array}{c}\text { Lei } 12.527 / 2011 \\
\text { (Art. } 8^{\circ} \S 1^{\circ} \text { Inciso IV) }\end{array}$ \\
\hline 5.3 & $\begin{array}{l}\text { A prefeitura divulga os contratos e termos aditivos } \\
\text { firmados? }\end{array}$ & $\begin{array}{c}\text { Lei } 12.527 / 2011 \\
\left(\text { Art. } 8^{\circ} \S 1^{\circ} \text { Inciso IV) }\right.\end{array}$ \\
\hline 5.4 & $\begin{array}{l}\text { A prefeitura divulga RELAÇÃO MENSAL de todas as } \\
\text { compras feitas pela administração direta e indireta? }\end{array}$ & $\begin{array}{c}\text { Lei } 9.755 / 98 \\
\text { (Art. } 1^{\circ} \text { Inciso VI) } \\
\text { - Lei } 8.666 / 93 \\
\text { (Art. 16) }\end{array}$ \\
\hline
\end{tabular}

